\title{
Doğu Anadolu Bölgesi İçin En Büyük Yer İvmesi Tahmini
}

\author{
Erdem Bayrak ${ }^{1 *}$ \\ ${ }^{1}$ Atatürk Üniversitesi, Oltu Yer Bilimleri Fakültesi, Jeoloji Mühendisliği Bölümü, Erzurum, Türkiye (ORCID: 0000-0001-9907-1463)
}

(Illk Geliş Tarihi 1 Ekim 2019 ve Kabul Tarihi 6 Kasım 2019)

(DOI: 10.31590/ejosat.637938)

ATIF/REFERENCE: Bayrak, E. (2019). Doğu Anadolu Bölgesi için En Büyük Yer İvmesi Tahmini. Avrupa Bilim ve Teknoloji Dergisi, (17), 676-681.

\begin{abstract}
$\ddot{O} z$
En büyük yer ivmesi (PGA), deprem tehlikesi değerlendirmeleri için önemli bir parametredir. Bu nedenle, PGA'nın hesaplanması için azalım ilişkileri geliştirilmiştir. Genel olarak bu ilişki deprem büyüklüğü ve episantr uzaklığı ile ilgilidir. Ayrıca araştırmacılar diğer parametrelere göre (zemin sınıflandırması, sismik hız vb.) farklı azalım ilişkileri geliştirmiştir. Bu çalışma, kuvvetli yer hareketi parametrelerinden PGA'yı Yapay Sinir Ağı (YSA) ile tahmin etmeyi amaçlamaktadır.

Yapay Sinir Ağı (YSA), teknolojinin gelişmesiyle birlikte literatürde artan etkin ve modern bir modelleme yöntemidir. Yapay Sinir Ağları, karmaşık olayları modellemek için geliştirilmiş matematiksel tasarımlardır. Jeofiziksel uygulamaların pek çok alanında da parametrelerin tahmini için YSA kullanılmıştır. Bu çalışmada, Doğu Anadolu Bölgesi’nde meydana gelen depremlerin en büyük yer ivmesini tahmin etmek için YSA kullanımı araştırılmışıtır. YSA modellerini eğitmek için TC Başbakanlık Afet ve Acil Durum Yönetimi Kurumu Deprem Dairesi Başkanlığı (AFAD) kuvvetli hareket istasyonları tarafından kaydedilen 128 deprem için toplam 564 kayıt kullanılmıştır. Çıktı verileri ise kaydedilen PGA'dan oluşur. Ayrıca, en büyük yer ivmesi ile diğer parametreler arasındaki ilişki (uzaklık, büyüklük) çoklu regresyon yöntemi kullanılarak incelenmiştir. Bazı istasyonlar için Vs30 hızları önceki çalışmalarla belirlenmiştir. Aynı işlem Vs30 parametresi eklenerek tekrarlanmış ve sonuçlar karşılaştırılmıştır. Ayrıca YSA tarafından tahmin edilen PGA ve regresyon analizi, birkaç azalım ilişkisine göre hesaplanan PGA ile karşılaştırılımıştır. Sonuçlar, YSA'nın azalım ilişkilerinden tahmin edilenden daha güvenilir ve gerçek benzeri PGA değeri verdiğini göstermektedir.
\end{abstract}

Anahtar Kelimeler: : En Büyük Yer İvmesi, Yapay Sinir Ağları, Çoklu Regresyon Analizi

\section{Estimation of the Peak Ground Acceleration for Eastern Turkey}

\begin{abstract}
The peak ground acceleration (PGA) is significant parameter for earthquake hazard assessments. Therefore attenuation relationships have been developed for calculating PGA according to strong-motion databases. Generally this relation has been related to the earthquake magnitude and epicenter distance. Besides researchers have formulated different attenuation relationships according to other parameters (such as soil classification, seismic velocity, etc ). This study aim to estimate the PGA with ANN trained by strongmotion databases.

Artificial Neural Network (ANN), efficient and modern modelling method which has increased in literature with development of technology. Artificial Neural Networks are mathematical tools design to perform complex pattern recognition tasks. They have been estimated parameters in many field also geophysical applications. The use of ANN is explored to predict peak ground accelerations for Eastern Turkey earthquakes. A total of 564 records for 128 earthquakes recorded by Republic of Turkey Prime Ministry Disaster and Emergency Management Authority Presidential of Earthquake Department (AFAD) strong motions stations are used to train the ANN models. The output data consist of the real recorded PGA. Also, the relationship between peak ground acceleration and other parameters (distance, magnitude) was investigated by using multiple regression method. Vs30 velocities for some stations were determined by previous studies. The same procedure was repeated by adding Vs30 parameter and the results were compared. Also the estimated PGA by ANN and regression analysis have been compared with calculated PGA according to several attenuation relationships. The results show that the ANN give more reliable and real-like PGA value than estimated from attenuation relationships.
\end{abstract}

Keywords: Peak Ground Acceleration, Artificial Neural Network, Multiple Regression Analysis

\footnotetext{
* Sorumlu Yazar: Atatürk Üniversitesi, Oltu Yer Bilimleri Fakültesi, Jeoloji Mühendisliği Bölümü, Erzurum, Türkiye (ORCID: 0000-0001-99071463), erdmbyrk@gmail.com
} 


\section{Giriş}

Depremlerin etkisinin incelenmesinde ve deprem tehlike analizlerinde genellikle en büyük yer ivmesi (PGA) kullanılmaktadır. PGA deprem büyüklüğü, episantr uzaklığı, zemin koşulları ve odak mekanizması ile ifade edilmekte olup, sıklıkla azalım ilişkileri kullanılarak hesaplanmaktadır. Bu parametreler arasındaki ilişkiler regresyon analizi ile belirlenmektedir. Depremin karmaşık yapısından dolayı bu değişkenlerin içerdiği belirsizlikler ivme tahminlerinde sapmalara sebep olmaktadır (Boore, 1983; Joyner, 1987; Joyner ve Boore, 1988; Anderson, 1991; Douglas, 2003; Somerville ve Graves, 2003, Güllü vd., 2007). Deprem oluşumunun karmaşık yapısından dolayı ivme tahminini doğru bir şekilde yapmak zordur (Douglas, 2003). Bu zorluğun başlıca nedeni ise regresyon analizinin doğrusal olmasıdır. Son yıllarda kullanılan Yapay Sinir Ağları (YSA) ise doğrusal olmayan sistemlerin de modellenmesini başarı ile yapabilmektedir. Bu çalışmada Doğu Anadolu'daki bazı depremler için hem YSA hem de Regresyon Analizi ile en büyük yer ivmesinin tahmin edilmesi ve bu iki yöntemin karşılaştırılması amaçlanmıştır.

\section{Materyal ve Metot}

\section{1. Çalışma Alanının Tektoniği ve Kullanılan Veri}

Çalışma alanı Türkiye'nin doğusunu kapsayacak şekilde $40^{0}-42.5^{0}$ boylamları ve $39^{0}-40.5^{0}$ enlemleri arasında kalan alanı içermektedir. Çalışma alanı Doğu Anadolu Tektonik Bloğu olarak adlandırılmakta, genellikle doğrultu atımlı fay zonlarını içermektedir (Şekil 1). Çalışma alanını etkileyen en büyük fay Kuzey Anadolu Fay Zonudur. Diğer büyük fay zonları ise ErzurumDumlu Fayı, Palandöken Fay Zonu, Aşkale Fay Zonu ve Horasan-Narman Fay Zonlarıdır. Erzurum ve civarı, depremsellik açısından çok aktif olan Kuzey Anadolu, Doğu Anadolu ve Kuzey Doğu Anadolu Fayları etkisi altında bulunmaktadır. Çalışma alanında hem aletsel hem de tarihsel dönemde birçok yıkıcı deprem oluşmuş ve büyük ölçüde can ve mal kaybına neden olmuştur. Bu depremlerden başlıcaları; 26 Aralık 1939'da Erzincan, 24 Kasım 1976 Çaldıran, 30 Ekim 1983 Horasan-Narman, 7 Aralık 1988 Spitak-Ermenistan ve 23 Ekim 2011 Tabanlı (Van) Ms = 7.2 depremleridir (Ambraseys, 2001; Cisternas vd., 1989; Eyidoğan vd., 1991; Irmak vd., 2012; Tan vd., 2008). 25 Mart 2004 Perşembe günü, Erzurum ili Aşkale ilçesinin yaklaşık 17 km doğusunda, saat 21.30'da (yerel saat) orta büyüklük $(\mathrm{Mw}=5.6)$ ve sığ-odaklı $(\mathrm{h}=10 \mathrm{~km})$ bir deprem meydana gelmiştir. Bu depremden üç gün sonra, $28 \mathrm{Mart} 2004$ Pazar günü, saat 06.51 'de (yerel saat), yine orta büyüklükte $(\mathrm{Mw}=5.5)$ ve sı̆̆-odaklı $(\mathrm{h}=5 \mathrm{~km})$ bir deprem meydana gelmiştir. Her iki deprem de Erzurum şehir merkezi, Aşkale, Ilıca, Çat, Kandilli ilçeleri ve aynı bölgede yer alan bir dizi köyü kapsayan bir alan üzerinde hissedilmiştir. Bu depremler nedeni ile özellikle Aşkale ilçesi civarındaki köylerde 9 kişi yaşamını yitirmiş ve yaklaşık 1300 yap1 ağır hasar görmüştür. Bu bölge aktif tektoniği nedeni ile jeolog ve jeofizikçilerin dikkatini çekmekte ve çok sayıda güncel çalışma bulunmaktadır (Koçyigit (2013), Öztürk ve Bayrak (2005), Üner vd., (2010), Koçyiğit ve Canoğlu (2017), Özer vd., (2018), Özer (2019a), Özer (2019b)).

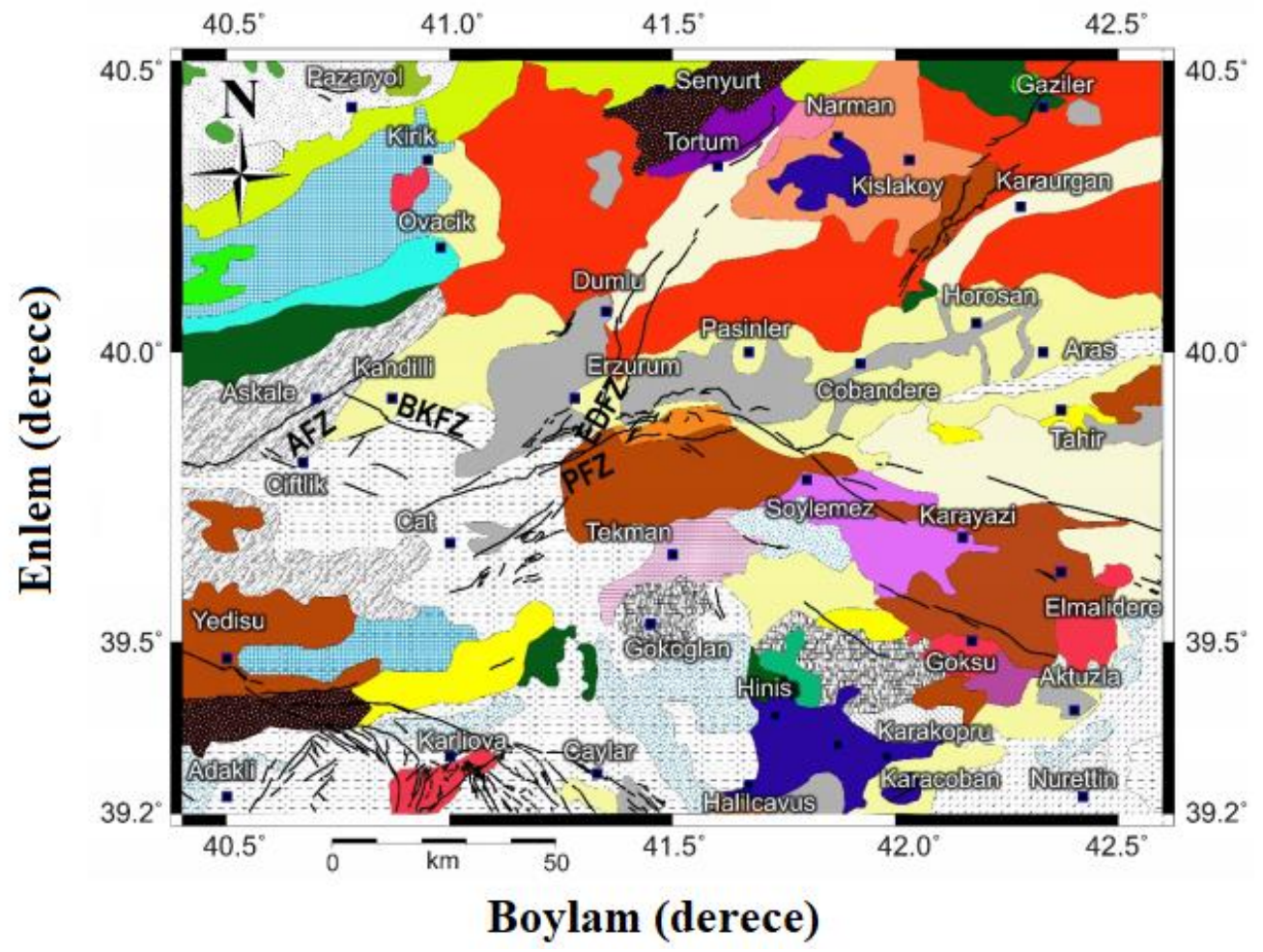

Şekil 1. Çalışma alanı jeolojisi ve aktiffaylar (Özer ve Yazıcıoğlu, 2019)

Çalışmada kullanılan deprem verisi 1994-2018 y1lları arasında meydana gelen magnitüdü 3-6 arasında değişen 128 adet depremden oluşmaktadır (Şekil 2). Bu depremlere ait toplam istasyon kayıt sayısı ise 564 adettir. Ayrıca depremlere ait episantr 
uzaklığı verileri de kullanılmıştır. Son olarak istasyonlara ait Vs30 hızları da hesaplamaya dâhil edilmiştir. Vs30 hız verisi ise 235 adettir. Episantr uzaklığı 2-257 km arasında, ivme değeri ise 0.01 ile 148 gal arasında değişmektedir (Şekil 3a-b).

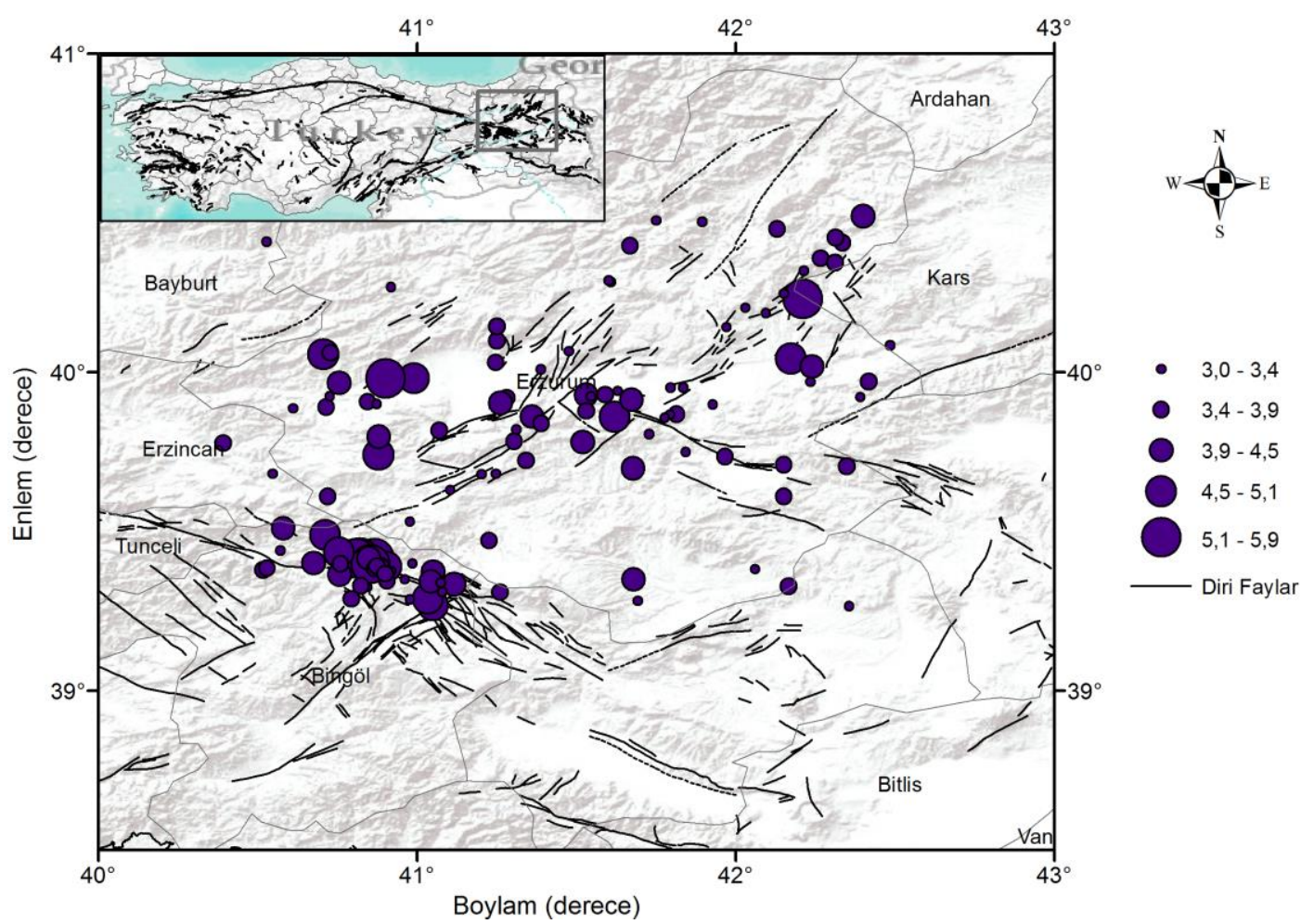

Şekil 2. Çalışmada kullanılan 128 adet depremin episantr dağılımı ve çalışma alanı

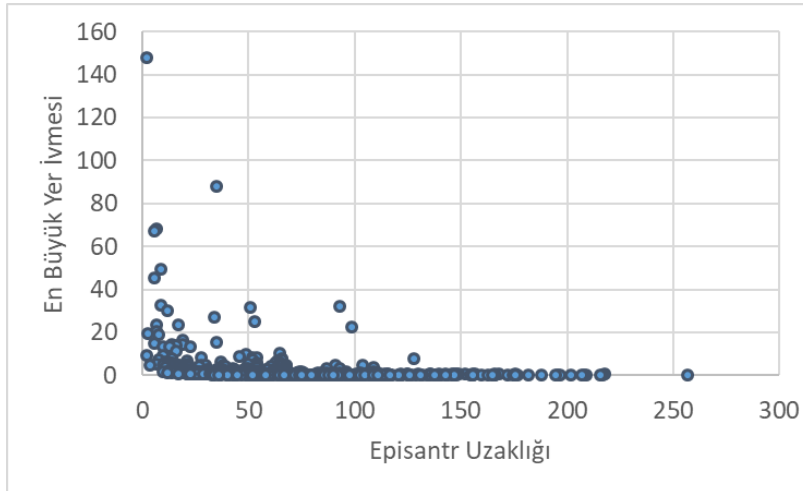

(a)

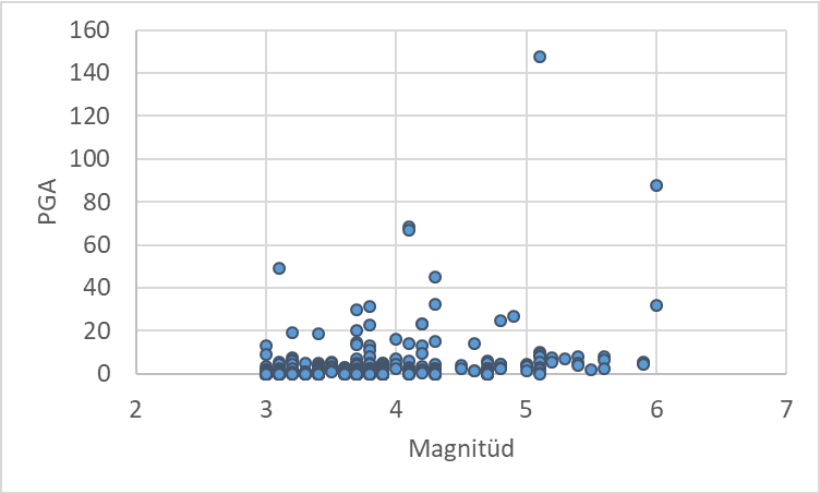

(b)

Şekil 3. a) Episantr uzaklı̆̆l-PGA grafiği b) Magnitüd-PGA grafiği

\subsection{En Küçük Kareler Yöntemi}

Regresyon analizi yaparken en çok kullanılan yöntemlerden biri en küçük kareler yöntemidir. En küçük kareler yöntemi, tıp, finans, mühendislik, ziraat, biyoloji ve sosyoloji gibi çeşitli bilim dallarında çeşitli değişkenler arasındaki ilişkiler belirlenirken kullanılan en önemli araçlar arasındadır.

EKKY ampirik bağıntı geliştirmek için sıkça kullanılan bir yöntemdir. Fakat bu yöntemin matematiksel ve istatistiksel olarak bazı sınırlamaları bulunmaktadır. Bu sınırlamalardan en önemlisi bağımlı değişken Y'nin bağımsız değişken X'e göre kesin olarak bilinmesinin gerekmesidir. Bağımlı ve bağımsız değişkenler $\mathrm{Y}=\mathrm{ax}+\mathrm{b}$ denklemindeki belirsizlikten etkilenirler (Castellaro vd., 2006).

\subsection{Yapay Sinir Ăgları}


İnsan beynini oluşturan sinir hücrelerinden önerilen bir yöntem olan Yapay Sinir Ağları (YSA) yöntemi kullanılmıştır. Bir sinir hücresinin (nöron) temelini; dendrid, sinaps ve akson oluşturmaktadır. Bunlardan dendrid bilgiyi alır, sinaps diğer birimlere aktarır ve akson ise geçiş yollarını oluşturur. Böylelikle, nörona verilen bir sinyal, birçok biyolojik nöronun bir araya gelmesiyle bilgiye dönüşmektedir.

Yer hareketi gibi doğrusal olmayan sistemlerin modellenmesinde çok katmanlı yapay sinir ağları kullanılmaktadır (Şen, 2004). Şekil 4'de çok katmanlı yapay sinir ağı modeli görülmektedir.

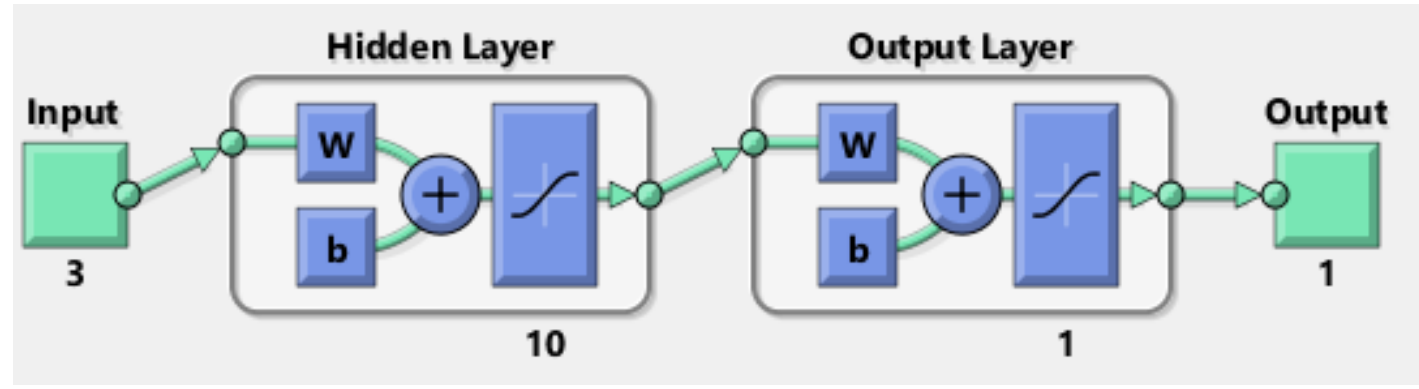

Şekil 4. Çok katmanlı yapay sinir ă̆ı modeli (Vs30 hızı kullanılmayan durumda giriş 3, kullanılan durumda ise girdi verisi 4 parametreden oluşmaktadır)

$\mathrm{Bu}$ çalışmada hata yayma modeli veya geriye yayım modeli (backpropagation network) olarak da bilinen çok katmanlı algılayıcı ağ modeli (ÇKA) (multilayer perception) kullanılmıştır. Bu yöntemde çözüm uzayını oluşturmak için hem girdiler hem de o girdilere karşılık çıktılar eğitim aşamasında eğitilir ve ağ bu verilere göre çözüm uzayını oluşturur. Daha sonra gösterilen benzer örnekler için bu çözüm uzayı sonuçlar üretmektedir (Güllü vd., 2007).

\section{Araştırma Sonuçları ve Tartışma}

YSA modelinde girdi olarak depremlerin büyüklüğü, episantr uzaklı̆̆ı, hiposantr derinliği ve Vs30 hızları, çıkış parametresi ise en büyük yer ivmesi olarak belirlenmiştir. Her istasyona ait Vs30 hızı bulunmadığı için, çalışmada iki model kullanılmıştır. Bunlardan ilki Vs30 hızı bilinen istasyonlarla, diğer modelde ise tüm istasyon verileri kullanılmıştır. Oluşturulan modellerde girdi katmanı 3, gizli katman 2 ve çıktı katmanı da 1 tabakadan oluşmakta olup, gizli katmandaki nöron sayısı 10 olarak tanımlanmıştır. Girdi katmanının \%70'i eğitim verisi olarak kullanılırken, \%30’u ise test verisi olarak kullanılmıştır. YSA'da İleri-beslemeli LevenbergMarquardt geri yayılım öğrenme algoritması kullanılırken, aktivasyon fonksiyonu olarak ise Tanjant Sigmoid kullanılmıştır.

Yapay Sinir Ağı ile yapılan analiz sonucunda, regresyon katsayısı \%80-88 arasında değişen sonuçlar elde edilmiştir (Şekil 5-6). $\mathrm{Bu}$ değerler, regresyonun başarılı olduğunu göstermektedir. İvmeler arasındaki korelasyon katsayısı Vs30 kullanıldığı durumda yaklaşık \%85 ve kullanılmadığı durumda ise \%88 bulunmuştur. Hata oranında ise ortalama hata kare (MSE) parametresi kullanılmış ve her iki durumda da yaklaşı MSE=0.20 elde edilmiștir. Çoklu Regresyon analizi ile Vs30 hızı kullanmadan yapılan analizde $\mathrm{R}^{2}=0.74$ ve MSE $=0.4$, Vs30 hızı kullanılarak yapılan analizde ise $\mathrm{R}^{2}=0.62$ ve MSE $=0.51$ elde edilmiştir. Bu değerlerin, karmaşık bir ortamda meydana gelen depremlerin modellenmesinde gayet makul sonuçlar olduğu ve girdi parametrelerinin arttırılması ile birlikte daha yüksek ilişki katsayısı elde edilebileceği düşünülmektedir. 

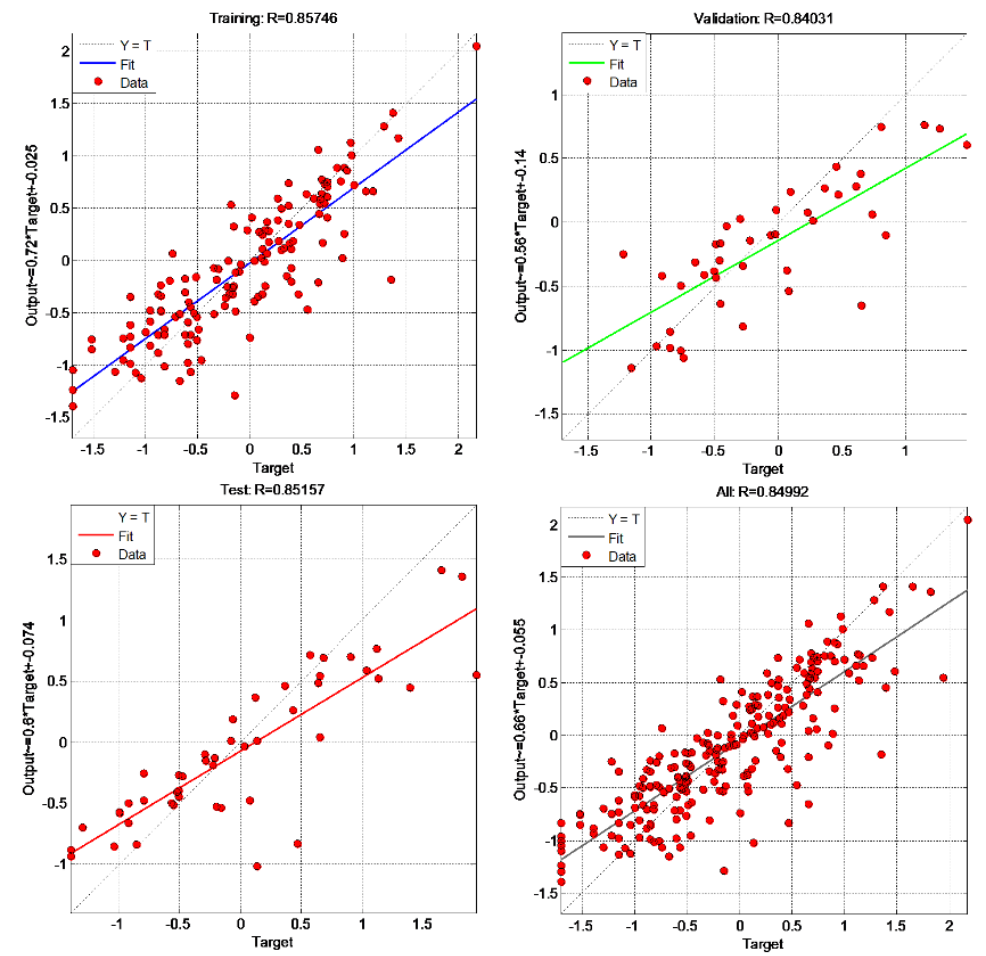

Şekil 5. a) Girdi verisinde Vs30 hızı kullanılarak hesaplanan YSA modeli
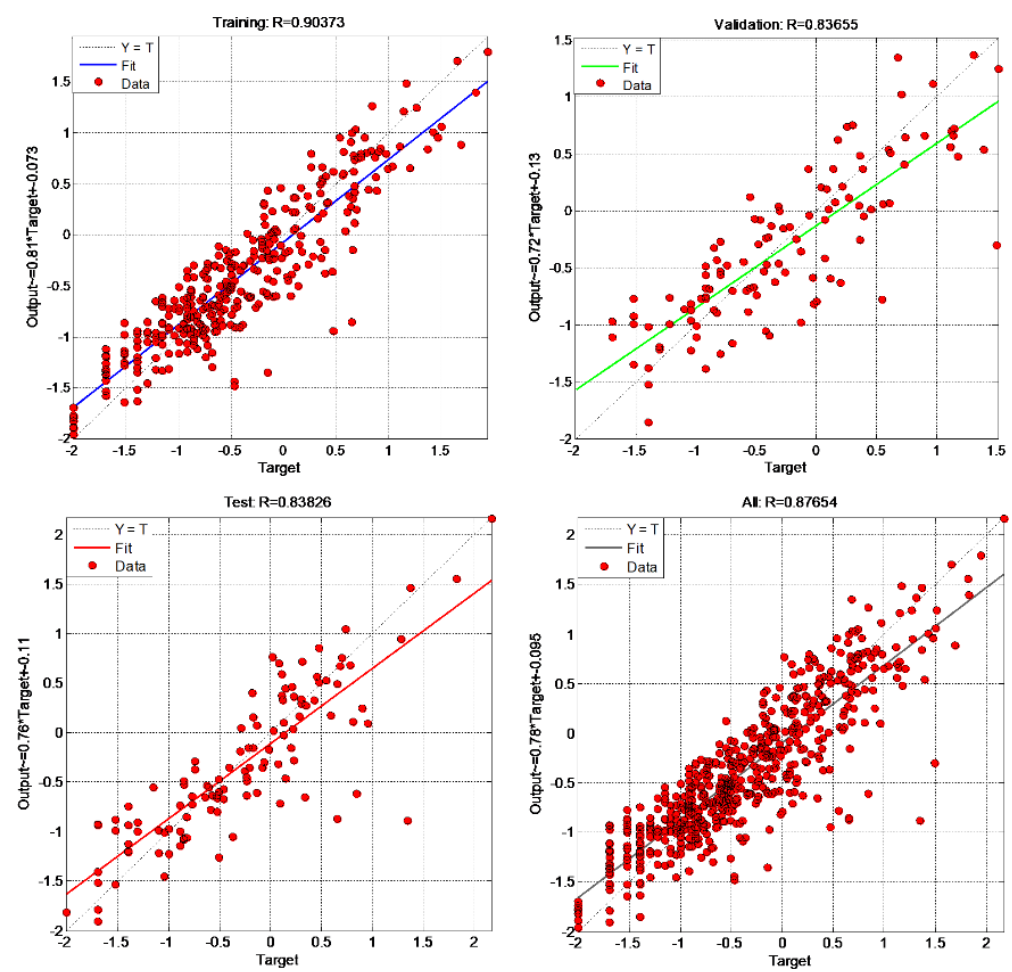

Şekil 6. Girdi verisinde Vs30 hızı kullanılmayarak hesaplanan YSA modeli sonuçları

\section{Sonuç}

Bu çalışma kapsamında, Doğu Anadolu Bölgesi'nde meydana gelen depremlerin ivmelerinin tahmin edilmesinde yapay sinir ağı ve regresyon analizlerinin performanslarının karşılaştırılması yapılmışıı. Çalışmada toplam 128 adet depreme ait 564 ivme kaydı kullanılmıştır. YSA'da ve regresyonda iki model oluşturulmuş, ilk model Vs30 hızı içerirken ikinci model bu parametreyi içermemektedir. Her iki yöntemle yapılan analiz sonucunda Vs30 hızı içeren modelin daha düşük ilişki katsayısı verdiği görülmüsştür. YSA ve regresyon modellerinin sonuçlarına bakıldığında ise, YSA ile yapılan analizde daha yüksek ilişki katsayısı elde edilmiştir. $\left(R_{Y S A, V S 30}^{2}=0.85, R_{C, R A, V S 30}^{2}=0.62 ; R_{Y S A}^{2}=0.88, R_{C, R A}^{2}=0.74\right)$. Deprem yerkürede meydana gelen olayların en karmaşıklarından bir tanesidir ve elde edilen ilişki katsayıları her iki durumda da gayet makul seviyelerde görülmektedir. Ancak bu performans, farklı YSA 
modellerinin seçilmesi, model parametrelerinin değiştirilmesi ile daha da yükseltilebilir. Bu sonuçlara göre, Yapay Sinir Ağı ivmelerin tahmin edilmesinde de kullanılabileceği açıkça görülmektedir. Bu çalı̧̧mada en büyük yer ivmesinin tahmininde yapay sinir ağı ve regresyon yöntemlerinin karşılaştırılması yapılmış ve yapay sinir ağının daha iyi sonuçlar ürettiği ortaya konulmuştur.

\section{Kaynakça}

Ambraseys, N. N. (2001). Reassesment of earthquakes. Geophysical Journal Internatinal, 145 (2) 471-485.

Anderson, J. G. (1991). Strong motion seismology. Reviews of Geophysics, 29, 700-720 (part 2).

Boore, D. M. (1983). Strong-motion Seismology. Reviews of Geophysics and Space Physics, 21 (6), 1308-1318.

Castellaro, S., Mulargia, F., \& Kagan, Y. Y. (2006). Regression Problems for Magnitude. Geophysical Journal International, 165 (3), 913-930.

Cisternas, A., Philip, H., J, C. B., Cara, M., Deschamps, A., Dorbath, L., \& Rivera, L. (1989). The Spitak (Armenia) earthquake of 7 December 1988: field observations, seismology and tectonics. Nature, 339(6227), 675.

Douglas, J. (2003). Earthquake ground motion estimation using strong motion records: a review of equations for the estimation of peak ground acceleration and response spectral ordinates. Earth-Science Reviews, 61 (1-2), 43-104.

Eyidoğan, H., Güçlü, U., Utku, Z., \& Değirmenci, E. (1991). Türkiye büyük depremleri makrosismik rehberi (1900-1988). İTÜ MF Jeofizik Mühendisliği Bölümü Yayınları.

Güllü, H., Pala, M., \& İyisan, R. (2007). Yapay Sinir Ağları ile En Büyük Yer İvmesinin Tahmin Edilmesi. Altıncı Ulusal Deprem Mühendisliği Konferansı. İstanbul.

Irmak, T. S., Doğan, B., \& Karakaş, A. (2012). Source mechanism of the 23 October, 2011, Van (Turkey) earthquake (M w= 7.1) and aftershocks with its tectonic implications. Earth, planets and space, 64 (11), 991-1003.

Joyner, W. B. (1987). Strong-motion seismology. Reviews of Geophysics, 25 (6), 1149-1160.

Joyner, W. B., \& Boore, D. M. (1988). Measurement, characterization, and prediction of strong ground motion. Proceedings of Earthquake Engineering and Soil Dynamics. II. Geotechnical Division, ASCE, 43-102.

Koçyiğit, A. (2013). New field and seismic data about the intraplate strike-slip deformation in Van region, East Anatolian plateau, Eastern Turkey. Journal of Asian Earth Sciences, 62, 586-605.

Koçyiğit, A., \& Canoğlu, M. C. (2017). Neotectonics and seismicity of Erzurum pull-apart basin, East Turkey. Russian Geology and Geophysics, 58, 99-122.

Özer, Ç., Özyazıcıŏglu, M., Gök, E., \& Polat, O. (2018). Imaging the Crustal Structure Throughout the East Anatolian Fault Zone, Turkey, by Local Earthquake Tomography. Pure and Applied Geophysics, 1-27.

Özer, Ç., \& Özyazıcıoğlu, M. (2019). The Local Earthquake Tomography of Erzurum (Turkey) Geothermal Area. Earth Sciences Research Journal, 209-223.

Özer, Ç. (2019a). Investigation of the Local Soil Effects of Erzurum and Its Surroundings Using SSR and HVSR Methods. DEU Journal of the Faculty of Engineering Journal of Science and Engineering, 21 (61), 247-257.

Özer, Ç. (2019b). Investigation of Soil Amplification in Lake Van Basin. Research Reviews in Engineering (Book Chapter) (s. 63-75, ISBN: 978-605-7631-38-1).

Öztürk, S., \& Bayrak, Y. (2005). 25 Mart 2004 Erzurum depremi, Md = 5.3, Artçı şok aktivitesi için sismisite parametreleri b ve p değerlerinin bölgesel değişimleri. II. Mühendislik Bilimleri Genç Arastirmacilar Kongresi, (s. 475-481). İstanbul.

Somerville, P. G., \& Graves, R. W. (2003). Characterization of earthquake strong ground motion. Pure and Applied Geophysics, 160, $1811-1828$.

Şen, Z. (2004). Yapy Sinir Ağları İlkeleri. İstanbul Su Vakfi.

Tan, O., Tapirdamaz, M. C., \& Yörük, A. (2008). The earthquake catalogues for Turkey. Turkish Journal of Earth Sciences, 17(2), 405-418.

Üner, S., Yesilova, Ç., Yakupoglu, T., \& Üner, T. (2010). Pekismemis sedimanlarda depremlerle olusan deformasyon yapilari (sismitler): Van Gölü Havzasi, Dogu Anadolu. Yerbilimleri, 31/1, 53-66. 